\title{
The Influence of One Hyperbaric Oxygen-Induced Seizure on Brain Eicosanoid Content
}

\author{
P. Mialon* and L. BaRThelemy \\ Laboratoire de Physiologie (IA CNRS 648), Faculté de Médecine, \\ 22, Av. Camille Desmoulins, BP 815, 29285 Brest, France
}

Received January 18, 1991; Accepted March 8, 1991

\begin{abstract}
The levels of prostaglandin $\mathrm{F}_{1}\left(6-\right.$ keto- $\left.\mathrm{PGF}_{1 \alpha}\right)$, thromboxane $\mathrm{B}_{2}$ (11-dehydro- $\left.\mathrm{TxB}_{2}\right)$, and peptidoleukotriene $\mathrm{C}_{4}\left(\mathrm{LTC}_{4}\right)$ were measured (acetylcholinesterase immunoassay) in the frontal cortex (FC) and the striatum (SA) of the rat brain to study the possible role of eicosanoids in seizures induced by hyperbaric oxygen ( $\mathrm{HBO}$ ). The rats were exposed to $(1)$ hyperbaric oxygen ( $\mathrm{HBO}, 6 \mathrm{ATA} \mathrm{O} \mathrm{O}_{2}$ ) up to the first seizure (2) compressed air (6 ATA air, i.e., $\cong 1.25 \mathrm{ATA} \mathrm{O}_{2}$ ) or (3) atmospheric pressure ( 1 ATA air, i.e., $0.21 \mathrm{ATA} \mathrm{O}_{2}$ ); there was no seizure in groups 2 and 3 . Transition from 6 ATA to atmospheric pressure was obtained in $15 \mathrm{~min}$; the rats were then decapitated and their heads frozen in liquid nitrogen before extraction and analysis of prostanoids. Whatever the conditions, cortical levels of 6-keto-PGF $1 \alpha$ and 11-dehydro-Tx $B_{2}$ are higher than striatal levels; considering the same area, 11-dehydro-Tx $\mathrm{B}_{2}$ and $\mathrm{LTC}_{4}$ concentrations were not significantly different whatever the condition, but there is a trend for lower 6-keto-PGF ${ }_{1 \alpha}$ levels in FC after $\mathrm{HBO}$ seizure. Biochemical mechanisms are discussed. Eicosanoids do not seem to play a major role in $\mathrm{HBO}$ seizures, although some modifications of their metabolism may take place.
\end{abstract}

Index Entries: Brain; eicosanoids; enzyme immunoassay; free radicals; hyperbaric oxygen toxicity; rat; seizure.

*Author to whom all correspondence and reprint requests should be addressed. 


\section{INTRODUCTION}

Prostaglandins (PG) and leukotrienes (LT) are normally present in the rat brain in very small amounts (Lindgren et al., 1984; Wolfe and Coceani, 1979). Electrically or chemically induced convulsions markedly increase free fatty acid content (Bazan, 1970; Siesjö et al., 1982) and subsequently PG content (Försterman et al., 1983) and LT (Simmet et al., 1988); this increase is not the only consequence of cerebral ischemia, a well-known stimulus of eicosanoid synthesis (Försterman et al., 1983), which may take place during some convulsions (Siesjö et al., 1982). Ionizing radiations damage tissues and increase PG content (Dubois et al., 1987); normobaric hyperoxia also damages tissues, but PG content varies with the considered tissue: it may decrease in vascular endothelium (an important target for both ionizing radiation and hyperoxia [Setty et al., 1984]) or increase in lung bronchoalveolar lavage fluid (PG and LT content, Smith et al., 1988). Free radicals have been suggested to play an important part in the initiation of $\mathrm{HBO}$-induced central nervous system (CNS) toxicity (Yusa et al., 1984) as, in general, $\mathrm{O}_{2}$ and ionizingradiation toxicities (Gerschman et al., 1954). Nevertheless there are contradictory reports on the exact role of free radicals in $\mathrm{HBO}$ CNS toxicity according to in vitro (Faiman et al., 1981, 1982) and in vivo models (Yusa et al., 1984). The results of pharmacological trials of PG synthesis inhibitor (Ruszczewski et al., 1979) suggest a role for PG in development of HBO seizure. Nevertheless, definitive interpretation of such pharmacological data is difficult, owing to the multiplicity of sites of action of drugs, eicosanoids, and $\mathrm{O}_{2}$. Many mechanisms may lead to generation of eicosanoids: during the first hyperoxic seizure there is no hypoxia (Mayevsky, 1984) at variance with electrically or chemically induced seizure; nevertheless, lipoperoxidation of cell membranes (Noda et al., 1983) and convulsion itself via increased neuronal activity (Försterman et al., 1983) may modulate prostanoid brain contents. However, in vitro lipid peroxidation induced by normobaric hyperoxia decreases arachidonic acid level (Rehncrona et al., 1980), so the final results upon eicosanoid brain content after $\mathrm{HBO}$ seizure is difficult to assess. To our knowledge, no data on brain eicosanoids content after the first $\mathrm{HBO}$ seizure are available. A study was therefore carried out to try to provide elements of answers to the following questions:

1. Is there a change in eicosanoid content of rat brain after the first HBO-induced seizure? (It might play a part in mechanisms of seizures.)

2. Is there any difference in cortical and striatal eicosanoid content after the first HBO-induced seizure? (As striatum is possibly inducing the HBO epileptic activity [Bertharion and Barthelemy, 1964; Mayevsky, 1984; Mialon et al., 1990], a great difference in levels in these two areas could be of interest.) 
No previous data was available; moreover, since the hyperbaric environment prevented access to animals in real time, only stable eicosanoid metabolites could be used, in order to reflect global changes in metabolism; LTC $_{4}$ was selected from among all leukotrienes because of its potential role in seizure (Simmet et al., 1988). Analyses were performed after the first seizure because only this seizure is HBO-specific; continuous exposition leads to status epilepticus and death, at which time the specificity of the initiating agent is lost among common and deep modifications in brain biochemistry, including prostanoids. Controls on rats at atmospheric pressure and at the same absolute pressure (6 ATA) as the $\mathrm{HBO}$ group, but in air ( $\cong 1.25 \mathrm{ATA}^{\mathrm{PIO}_{2}}$ ), were added: at this oxygen partial pressure there is no nervous toxicity in rats (Clark, 1974, for review), but, as an effect of pressure might be possible, it should be assessed.

\section{MATERIALS AND METHODS}

Sprague-Dawley mature male rats (weight $200-250 \mathrm{~g}$ ) were received from the supplier (Charles Rivers, France) 1 wk prior to use, housed in a quiet room (temperature $19-23^{\circ} \mathrm{C}$, natural day/night cycle) and maintained on same diet (Extralabo Ets Pietrements, Provins, France) and water ad libidum except for $4 \mathrm{~h}$ before the experiments, when food was withdrawn. The care and treatment of the animals were managed according to the Principles of Care and Use of Experimental Animals of the French Agricultural Department.

Every experiment took place between 10 and $12 \mathrm{AM}$. The rats were divided into three groups: one exposed to $6 \mathrm{ATA} \mathrm{O}_{2}$ until the first seizure, one exposed to 6 ATA air, and another exposed to 1 ATA air for an equivalent time (the sum of the compression time and the time elapsed between the end of compression and the beginning of the first seizure, taking into account previous work [Mialon et al., 1990]).

\section{Hyperbaric Oxygen Exposure}

\section{HBO Group}

The $\mathrm{HBO}$ group was composed of seven rats, exposed individually to 6 ATA $\mathrm{O}_{2}$ in a small hyperbaric tank $(45 \mathrm{~L})$, up to the first clinical seizure. The tank was free of $\mathrm{CO}_{2}$ (soda lime absorber); internal temperature was $22 \pm 1^{\circ} \mathrm{C}$. The tank was fitted with two portholes, allowing constant visual monitoring of the animals. It was flushed with $\mathrm{O}_{2}$ until the oxygen concentration $\left(\mathrm{FIO}_{2}\right)$ was $>0.95\left(\mathrm{O}_{2}\right.$ analyzer Beckman D2). The pressure was then increased to 6 ATA with pure medical oxygen (compression time, $5 \mathrm{~min}$ ). Immediately after the onset of the first clinical seizure (11.2 $\pm 1.1 \mathrm{~min}$ after the start of compression), the chamber was flushed with compressed air (6 ATA, 2 min) in order to lessen $\mathrm{FIO}_{2}$ to $\neq 30 \%$ and avoid iterative seizure. Decompression lasted $15 \mathrm{~min}$, under 
constant visual control without any risk of overpressure of the lung. If a rat convulsed more than once, it was not used for the study.

\section{Pressure Air (PA) Group}

The "pressure air group" (PA) was composed of seven rats, exposed individually to 6 ATA air. Compression time was 5 min, exposure was maintained for $10 \mathrm{~min}$, and the chamber was then flushed at 6 ATA with air for 2 min (to mimic auditive stimulations of the $\mathrm{HBO}$ group when ventilated with air after the seizure). Decompression lasted $15 \mathrm{~min}$. In simulated dives, for these durations and pressure, rats did not develop decompression sickness.

\section{Atmospheric Control (AC) Group}

The "atmospheric control group" (AC) was composed of seven rats, left individually for $35 \mathrm{~min}$ in the chamber with atmospheric pressure. A low air flow (5 L/min) was applied during the first $5 \mathrm{~min}$, and then from the 15 th to the 35 th min, to mimic the auditive stimulations of both $\mathrm{HBO}$ and PA groups.

After its removal from the tank, each animal was instantly decapitated $(<1 \mathrm{~min})$. The heads were immediately frozen in liquid nitrogen and, $5 \mathrm{~min}$ later, transferred into ice-cold methanol, where they were allowed to thaw gradually. The brains were then removed in toto. Three samples were taken from the right $\mathrm{FC}$, and three more from the left SA. Each one was weighed in liquid nitrogen and transferred to $-80^{\circ} \mathrm{C}$.

\section{Analytical Technique}

One of the three pieces of brain tissue was sonicated in $1 \mathrm{~mL}$ of methanol/water $(10 / 90 \% \mathrm{v} / \mathrm{v})$. After centrifugation $\left(15 \mathrm{~min}, 2000 \mathrm{~g},+4^{\circ} \mathrm{C}\right)$, the supernatant was injected into a C18 J. T. Baker (Phillipsburg, NJ, USA) column (1mL) prewashed successively with $5 \mathrm{~mL}$ of methanol/ EDTA $0.5 \%(50 \% / 50 \% \mathrm{v} / \mathrm{v}), 5 \mathrm{~mL}$ of methanol, and $5 \mathrm{~mL}$ of water. The whole sample went through the column, which was then washed with 5 $\mathrm{mL}$ of hexane. Elution used $5 \mathrm{~mL}$ of ethanol. These procedures are derived from Luderer et al., 1983, and Salari and Steffenrud, 1986, being a compromise between optimal conditions for all products. Eluates were lyophilized. Residues were resuspended in $400 \mu \mathrm{L}$ of enzyme immunoassay (EIA) buffer and $50 \mu \mathrm{L}$ was used for each analysis. Assessment of extraction efficiency used labeled synthetic PG and LT (New England Nuclear, Boston, MA, USA). As only a single piece from each sample was used for analysis, the two remaining pieces were labeled before sonication with $0.01 \mu \mathrm{Ci}$ tritiated 6-keto-PGF ${ }_{1 \alpha},(120-180 \mathrm{Ci} / \mathrm{mmol})$ and with tritiated $\mathrm{LC}_{4}(20-60 \mathrm{Ci} / \mathrm{mmol})$, respectively, and then went through the previously described procedures. Residue was resuspended in $1 \mathrm{~mL}$ of methanol/water $(90 / 10 \% \mathrm{v} / \mathrm{v})$ with $4 \mathrm{~mL}$ of scintillation cocktail (Insta Gel, Packard Instrument Corporation, Downers Grove, IL, USA). Radioactivity was determined by using a liquid scintillation $\beta$ counter (Rack 
Beta 1214, LKB, Bromma, Sweden). For each labeled piece the ratio of actual count to added count was calculated, giving extraction efficiency.

Analysis of prostanoids used solid-phase EIA; this analytical technique of eicosanoids is equivalent and simpler than standard RIAA (Pradelles et al., 1985). All these EIA kits may be purchased from Cayman Chemical (Ann Arbor, MI, USA). To each well of a 96-well microtiter plate previously coated with IgG antibody were added first $50 \mu \mathrm{L}$ of each sample, then $50 \mu \mathrm{L}$ of enzymatic tracer (acetylcholinesterase), and last $50 \mu \mathrm{L}$ of specific rabbit antiserum (6-keto-PGF $\mathrm{PG}_{1 \alpha}$ or 11 -dehydro- $\mathrm{TxB}_{2}$ or $\mathrm{LTC}_{4}$ ). After $18 \mathrm{~h}$ of incubation $\left(4^{\circ} \mathrm{C}\right)$ the plates were washed two times with a mixture of phosphate-buffered saline and Tween $20(0.05 \%)$, and then filled with $200 \mu \mathrm{L}$ of Ellman's reagent. After a while, optic density of the yellow product was read with a Multiscan (Titertek, Flow Laboratories, Pureaux, France). Each sample was assayed in duplicate at two different dilutions. Standards were assayed on each plate at concentrations ranging from 0.25 to $100 \mathrm{pg} /$ well. Nonspecific binding was determined by using an incubation mixture in which the specific antibody was replaced by $50 \mu \mathrm{L}$ of assay buffer. The amount of tracer bound in the absence of prostaglandin or leukotriene $\left(B_{0}\right)$ was determined by replacing standard or sample with $50 \mu \mathrm{L}$ of assay buffer. A standard curve was obtained by plotting $\mathrm{B} / \mathrm{B}_{0} \%$ (the absorbance measured on the bound fraction with prostanoid divided by the absorbance in the absence of competitor) vs picograms of standard, by well. Fitting the standard curve and calculating the quantity of prostanoid in samples were performed with a nonlinear curve-fitting program (Pradelles et al., 1985). Sensitivities were, respectively, $0.45,2$, and $3 \mathrm{pg} /$ well for 11-dehydro- $\mathrm{TkB}_{2}, 6$ keto-PGF ${ }_{1 \alpha}$, and $\mathrm{LTC}_{4}$; 11-dehydro-TxB ${ }_{2}$ was selected because its reliability is better than that of $\mathrm{TXB}_{2}$, as it cannot be released from activated platelets (Granström and Kumlin, 1987); indeed, conversion from glial $\mathrm{TxB}_{2}$ to 11-dyhydro- $\mathrm{TxB}_{2}$ is mostly extraneural, but Grandström and Kumlin (1987) have shown that in some tissue this conversion takes place only when NAD is added. During the first HBO seizure the oxidation of nucleotides results in very high levels of NAD (Mayevsky, 1984), so we suspected the conversion was possible. Simultaneous analysis of $\mathrm{TxB}_{2}$, though logical, has not been performed, as major coagulation interference takes place when $\mathrm{TxB}_{2}$ from brain samples is analyzed without microwave irradiation (20-fold increase in $\mathrm{TxB}_{2}$ level, Anton et al., 1983), precluding any interpretation from such data. The final results obtained from EIA-plate data were corrected for volume and extraction efficiency. Tritiated 11-dehydro- $\mathrm{Tx}_{2}$ was not available; nevertheless, recovery rates for 6-keto- $\mathrm{PGF}_{1 \alpha}$ and $\mathrm{T}_{\mathrm{B}} \mathrm{B}_{2}$ do not differ much (5\%, Luderer et al., 1983), so the same value was taken for both compounds.

\section{Statistics}

Statistical analysis of data was carried out at the $5 \%$ level by analysis of variance (ANOVA). 


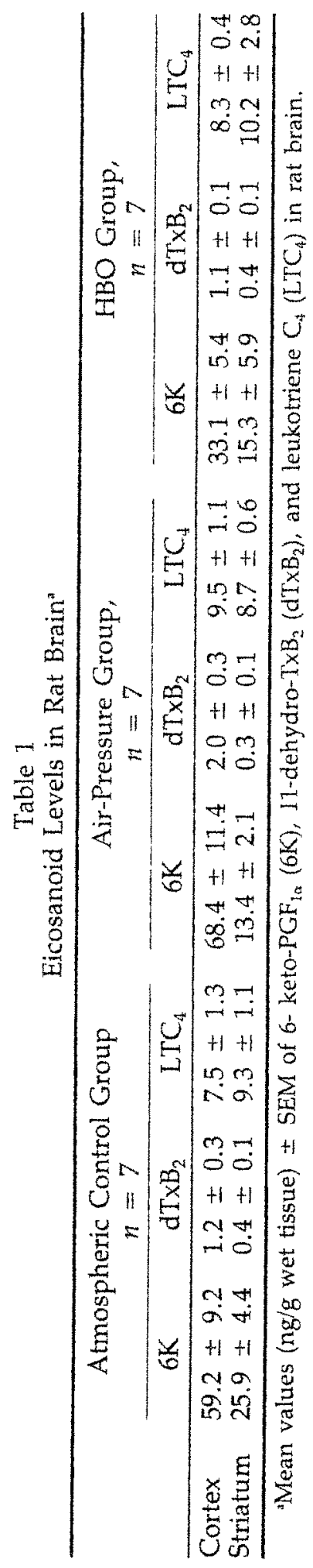




\section{RESULTS}

The results are given in Table 1 . Extraction efficiency was roughly $50 \%$ for PG and $20 \%$ for $\mathrm{LTC}_{4}$. The eicosanoid values are high, but in keeping with the method of killing (Anton et al., 1983). Whatever the environmental conditions, regional differences between $\mathrm{FC}$ and $\mathrm{SA}$ are found for 6-keto- $\mathrm{PGF}_{1 \alpha}$ and 11-dehydro- $\mathrm{TBB}_{2}(\mathrm{FC}>\mathrm{SA})$ at variance with $\mathrm{LTC}_{4}$. Regional differences could be the result of decapitation, as suggested by the results of Anton et al. (1983); nevertheless, the duration of dissection was quite similar, FC always taken first, and, moreover, congelation proceeds from cortex to striatum: thus it may seem doubtful that the constancy of the gradient between FC and SA is totally explained by sampling maneuvers. Neither the HBO nor the PA group differs significantly (at the $5 \%$ level) from the $\mathrm{AC}$ group, though there is a nonsignificant trend for $\mathrm{HBO}$ to lower 6-keto- $\mathrm{PGF}_{1 \alpha}$ levels ( $\mathrm{HBO}$ vs $\mathrm{AC}$ in $\mathrm{FC}$.) Hence, neither pressure, $\mathrm{PIO}_{2}$, tissue $\mathrm{PO}_{2}$ nor convulsion seems to have a major impact on eicosanoid metabolism under our experimental conditions, though a possible effect of $\mathrm{HBO}$ on $6-\mathrm{keto}-\mathrm{PGF}_{1 \alpha}$ content cannot be precluded, because of the small size of our samples.

\section{DISCUSSION}

Eicosanoid brain levels in the $\mathrm{HBO}$ group were not higher than in the $A C$ group, despite some reports of PG and LT elevation during seizures of various origins (Försterman et al., 1983; Simmet et al., 1988), or during free-radical generation (Dubois et al., 1987; Smith et al., 1988). One could object that sampling conditions may have modified the results: decapitation and immediate immersion in liquid nitrogen, though imperfect, is classical (Bazan, 1970; Försterman et al., 1983; Lindgren et al., 1984; Simmet et al., 1988). If the brain remains in the head for $1 \mathrm{~min}$, there is little difference between microwave irradiation and decapitation in terms of levels of free fatty acid (Cenedella et al., 1975). There is always a possibility that prostanoid tissue levels may have been modified by the killing procedures, whatever they may be; however, as timing of procedures is very similar for all experiments $(80 \pm 10 \mathrm{~s})$, differences between groups would stay unchanged. Another factor of variation is time of sampling: analyses in the $\mathrm{HBO}$ and air-pressure group were delayed after seizure because of flushing with compressed air and decompression ( $\cong 17 \mathrm{~min}$ ). This delay cannot be shortened further: explosive decompression kills the animal and strongly interferes with any action of $\mathrm{HBO}$ on prostanoid metabolism, and too short a decompression induces formation of silent bubbles in vessels with membrane activation and possible hidden ischemia (air-pressure group, not $\mathrm{HBO}$ ). However, as the analyses were delayed, it may be possible to speculate that brain eicosanoid content may have increased during hyperbaric seizure and quickly de- 
creased during decompression to control levels. But the assayed products have different and slow turn-over: $20 \mathrm{~min}$ after revascularization following partial ischemia of the rat brain, concentrations of $\mathrm{TxB}_{2}, 6$-keto$\mathrm{PGF}_{1 \alpha}$ and $\mathrm{LTC}_{4}$ are still, respectively, 4,2 , and 3 times higher than control levels; furthermore, $\mathrm{LTC}_{4}$ increases up to the 45 th $\mathrm{min}$ (Minamisawa et al., 1988). The results of Shohami et al., (1982) and Jacobs et al., (1987) are also consistent with stability of produced eicosanoids for delays longer than $15 \mathrm{~min}$. During HBO exposure there is an immediate cerebral vasoconstriction, with only transient vasodilation during the seizure and with return to initial tone at least at the end of the first seizure (Mayevsky, 1984). During most of the decompression cerebral vasoconstriction takes place, as the animals are in hyperoxic ambiance. Therefore a total washout of a putative transient cerebral elevation of prostanoids is very unlikely. Moreover, after one $\mathrm{HBO}$ seizure, there is a tendency for 6-keto- $\mathrm{PGF}_{1 \alpha}$ levels to decrease (at least in FC). How then is one to explain the results? If lipid peroxidation of cell membranes occurs during the first $\mathrm{HBO}$ seizure (convulsion and membrane modifications), a rapid increase in the levels of free fatty acids, including arachidonic acid (AAc), should occur. As the usual biosynthesis of eicosanoids is regulated via substrate availability, subsequent accumulation of stable final products is expected. Our results suggest that available AAc does not increase and/or that AAc and other fatty acid changes are balanced as some unsaturated fatty acids compete with AAc (Lands and Kulmacz, 1984). Because Rehncrona et al. (1980) found a slight decrease in AAC and decohexaenoic acid levels in parallel with in vitro lipid peroxidation $\left(1\right.$ ATA $\left.\mathrm{O}_{2}\right)$, the first hypothesis seems more likely. One should also consider that the two major enzymatic pathways (cyclooxygenase for PG and 5-lipoxygenase and $\mathrm{LTC}_{4}$ synthase for LT) might also be inactivated by $\mathrm{HBO}$ exposure. Setty et al. (1984) found a $30 \%$ decrease in $V_{\max }$ of vascular tissue cyclooxygenase exposed 15 min to $1 \mathrm{ATA} \mathrm{O}_{2}$, so greater inactivation when exposed to $6 \mathrm{ATA} \mathrm{O}_{2}$ is likely (endothelium is a "firstline" target). The same conclusions regarding cyclooxygenase inactivation by reactive oxygen species can be drawn from the work of Hempel et al. (1990). We have no data on 5-lipoxygenase activity in $\mathrm{HBO}$, but $\mathrm{LTC}_{4}$ synthase is dependent on the intracellular concentration of glutathione (GSH; Shimizu, 1988), which could change during HBO (oxydation of GSH to GSSG in relation to the metabolism of free radicals, McCord and Fridovitch, 1978). Local ionic variations in the brain during seizure (Mayevsky, 1984) could lead to a greater enzyme inactivation. However, as eicosanoid levels are high within both groups, one has to admit that the synthesis of enzymes in brain is normal at the time of decapitation; this is suggestive of minimal HBO enzyme inactivation, for it is usually slow to reverse (Faiman et al., 1981). Moreover, after the first hyperoxic seizure there are no great histological, neuronal, astrocytic, or vascular abnormalities (Balentine, 1982). Considering that, a major role of enzyme HBO transient inactivation seems unlikely, but it is a possible additive factor in 
conditions of restricted availability of substrate, and this could explain the trend to lower 6-keto- $\mathrm{PGF}_{1 \alpha}$ levels in the $\mathrm{HBO}$ group. Considering that point of view our results seem more consistent with those of Yusa et al. (1984), which implicate the formation of free radicals in rat brain at the beginning of the first $\mathrm{HBO}$ seizure, than with those of Faiman and Dirks (1982), who found no formation of free radicals in the same in vivo conditions. A direct evaluation of AAc levels and activity of enzymes in HBO conditions, however, is necessary to give more detailed information on all steps of prostanoid metabolism, but the observed preliminary results do not support the idea that eicosanoids could play a major role in initiation of HBO seizures, although some modifications in the whole metabolism could occur after one $\mathrm{HBO}$ seizure.

\section{ACKNOWLEDGMENTS}

The authors wish to thank Ph. Pradelles (LERI/SPI, CEN SACLAY, 91191, GIF/S/YVETTE, France) for the generous gift of EIA kits and invaluable technical assistance and $\mathrm{Mr}$. Torillec for skillful assistance during $\mathrm{HBO}$ experiments.

\section{REFERENCES}

Anton R. F., Wallis C., and Randall C. L. (1983) In vivo regional levels of PGE and thromboxane in mouse brain: Effect of decapitation, focused microwave fixation, and indometacin. Prostaglandins 26, 421-429.

Balentine J. D. (1982) Pathology of Oxygen Toxicity (Academic, New York).

Bazan N. G. (1970) Effects of ischemia and electroconvulsive shock on free fatty acid pool in the brain. Biochem. Biophys. Acta 218, 1-10.

Bertharion G. and Barthelemy L. (1964) Effet aigu de l'oxygène hyperbare. Agressologie 5, 583-593.

Cenedella R. J., Galli C., and Paoletti R. (1975) Brain free fatty acid levels in rats sacrificed by decapitation versus focused microwave irradiation. Lipids 10, 290-293.

Clark J. M. (1974) The toxicity of oxygen. Am Rev. Respir. Dis. 110, 40-50.

Dubois A., Danquechin Dorval E., Steel L., Fiala N. P., and Conklin J. J. (1987) Effect of ionizing radiation on prostaglandins and gastric secretion in rhesus monkeys. Radiat. Res. 110, 289-293.

Faiman M. D., Nolan R. J, Dodd D. E., Waetchter J. M., Dirks R. C., Haya K., and Zempel J. A. (1981) Mechanism(s) of central oxygen toxicity: A reevaluation, in Underwater Physiology VII (Barach A. J. and Matzen M. M., eds.), pp. 25-36, Undersea Medical Society, Bethesda, MD.

Faiman M. D. and Dirks R. C. (1982) Free radical-induced lipid peroxidation and ion flux as a mechanism in oxygen $\left(\mathrm{O}_{2}\right)$ convulsions. Undersea Biomed. Res. 9, (Suppl. 1) 38 .

Försterman U., Heldt R., and Hertting G. (1983) Increase in brain prostaglandins during convulsions is due to increased neuronal activity and not to hypoxia. Arch. Int. Pharmacodyn. 263, 180-188. 
Gerschman R., Gilbert D. L., Nye S. W., Dwyer P., and Fenn W. O. (1954) Oxygen poisoning and $X$-irradiation: A mechanism is common. Science 119, $623-626$.

Granström E., and Kumlin M. (1987) Assay of thromboxane production in biological systems: Reliability of TXB2 versus 11 dehydro TXB2 as targets for measurement, in Advances in Prostaglandin, Thromboxane, Leukotriene Research (Samuelson B., Paoletti R., and Ramwell P. W., eds.), vol. 17, pp. 587-594, Raven, New York.

Hempel S. L., Haycraft D. L., Hoak J. C., and Spector A. A. (1990) Reduced prostacyclin formation after reoxygenation of anoxic endothelium. Am. J. Physiol. (Cell Physiol. 28), C738-C745.

Jacobs T. P., Shohami E., Baze W., Burgard E., Gunderson C., Hallenbeck J. M., and Feuerstein G. (1987) Deteriorating stroke model: Histopathology, edema and eicosanoid changes following spinal cord ischemia in rabbits. Stroke 18, 741-750.

Lands W. E., and Kulmacz R. J. (1984) The regulation of the biosynthesis of prostaglandins and leukotrienes. Prog. Lipid Res. 25, 105-109.

Lindgren J. A., Hökfelt T., Dahlen S., Patrono C., and Samuelsson B. (1984) Leukotrienes in the rat central nervous system. Proc. Natl. Acad. Sci. USA 81, 6212-6216.

Luderer J. R., Riley D. L., and Demers L. M. (1983) Rapid extraction of arachidonic acid metabolites utilizing octadecyl reversed-phase columns. J. Chromatogr. 273, 402-409.

Mayevsky A. (1984) Brain oxygen toxicity, in Underwater Physiology VIII (Barach A. J. and Matzen M. M., eds.) pp. 69-89, Undersea Medical Society, Bethesda, MD.

McCord J. M., and Fridovitch I. (1978) Biology and pathology of oxygen radicals. Ann. Int. Med. 89, 122-127.

Mialon P., Caroff J., Barthelemy L., and Bigot J. C. (1990) Ammonia and monoamines concentrations in two brain areas in rats after one hyperoxic seizure. Aviat. Space Environ. Med. 61, 28-32.

Minamisawa H., Terashi A., Katayama Y., Kanda Y., Shimizu J., Shiratori T., Inamura K., Kaseki H., and Yoshino $Y$. (1988) Brain eicosanoid levels in spontaneously hypertensive rats after ischemia with reperfusion: Leukotriene C4 as a possible cause of cerebral edema. Stroke 19, 372-377.

Noda Y., McGreer P. L., and McGreer E. G. (1983) Lipid peroxide distribution in brain and the effect of hyperbaric oxygen. J. Neurochem. 40, 1329-1332.

Pradelles P., Grassi J., and Maclouf J. (1985) Enzyme immunoassays of eicosanoids using acetylcholine esterase as label: An alternative to radioimmunoassay. Anal. Chem. 57, 1170-1173.

Rehncrona S., Smith D. S., Akesson B., Westerberg E., and Siesjö B. K. (1980) Peroxidative changes in brain cortical fatty acids and phospholipids, as characterized during $\mathrm{Fe}^{2+}$ and ascorbic acid-stimulated lipid peroxidation in vitro. J. Neurochem. 34, 1630-1638.

Ruszczewski P., Truskolaski P., Dabrowiecki Z., Rap Z. M., and HerbaczynskaCedro K. (1979) Effect of prostaglandin E2 and of Indomethacin upon cerebral and pulmonary consequences of exposure to hyperbaric oxygen in rats. Acta Neurol. Scandinav. 59, 188-199. 
Salari H. and Steffenrud S. (1986) Comparative study of solid phase extraction techniques for isolation of leukotrienes from plasma. J. Chromatogr. 378, 3544.

Setty B. N. Y., Walenga R. W., and Stuart M. J. (1984) Kinetic analyses of the effect of hyperoxia and hypoxia on vascular cyclooxygenase activity in vitro. Biochem. Biophys. Res. Commun. 125, 170-176.

Shimizu T. (1988) Enzymes functional in the syntheses of leukotrienes and related compounds. Int. I. Biochem. 20, 661-666.

Shohami E., Rosenthal J., and Lavy S. (1982) The effect of incomplete cerebral ischemia on prostaglandin levels in rat brain. Stroke 13, 494 498.

Siesjö B. K., Ingvar M., and Westenberg E. (1982) The influence of bicucullineinduced seizures on free fatty acid concentrations in cerebral cortex, hippocampus and cerebellum. J. Neurochem. 39, 796-802.

Simmet T., Seregi A., and Hertting G. (1988) Characterization of seizureinduced cysteinyl-leukotriene formation in brain tissue of convulsion-prone gerbils. $J$. Neurochem. 50, 1738-1742.

Smith L. J., Shamsuddin M., Anderson J., Hsueh W. (1988) Hyperoxic lung damage in mice: Appearance and bioconversion of peptide leukotrienes. I. Appl. Physiol. 64, 944-951.

Wolfe L. S. and Coceani F. (1979) The role of prostaglandins in the central nervous system. Annu. Rev. Physiol. 41, 669-684.

Yusa T., Crapo J. D., and Freeman B. A. (1984) Liposome-mediated augmentation of brain SOD and catalase inhibits CNS O2 toxicity. J. Appl. Physiol.: Respir. Environ. Physiol. 57, 1674-1681. 